\title{
Discussion of "Rigid Water Column Model for Simulating the Emptying Process in a Pipeline Using Pressurized Air" by Oscar E. Coronado-Hernandez, Vicente S. Fuertes-Miquel, Pedro L. Iglesias-Rey, and Francisco J. Martinez-Solano
}

Citation for published version (APA):

Hou, Q., Li, S., Tijsseling, A. S., \& Laanearu, J. (2020). Discussion of "Rigid Water Column Model for Simulating the Emptying Process in a Pipeline Using Pressurized Air" by Oscar E. Coronado-Hernandez, Vicente S. Fuertes-Miquel, Pedro L. Iglesias-Rey, and Francisco J. Martinez-Solano. Journal of Hydraulic Engineering, 146(3), [07020001]. https://doi.org/10.1061/(ASCE)HY.1943-7900.0001682

\section{Document license:}

TAVERNE

DOI:

10.1061/(ASCE)HY.1943-7900.0001682

Document status and date:

Published: 01/03/2020

Document Version:

Publisher's PDF, also known as Version of Record (includes final page, issue and volume numbers)

Please check the document version of this publication:

- A submitted manuscript is the version of the article upon submission and before peer-review. There can be important differences between the submitted version and the official published version of record. People interested in the research are advised to contact the author for the final version of the publication, or visit the $\mathrm{DOI}$ to the publisher's website.

- The final author version and the galley proof are versions of the publication after peer review.

- The final published version features the final layout of the paper including the volume, issue and page numbers.

Link to publication

\footnotetext{
General rights

- You may freely distribute the URL identifying the publication in the public portal. follow below link for the End User Agreement:

www.tue.nl/taverne

\author{
Take down policy \\ If you believe that this document breaches copyright please contact us at: \\ openaccess@tue.nl \\ providing details and we will investigate your claim.
}

Copyright and moral rights for the publications made accessible in the public portal are retained by the authors and/or other copyright owners and it is a condition of accessing publications that users recognise and abide by the legal requirements associated with these rights.

- Users may download and print one copy of any publication from the public portal for the purpose of private study or research.

- You may not further distribute the material or use it for any profit-making activity or commercial gain

If the publication is distributed under the terms of Article 25fa of the Dutch Copyright Act, indicated by the "Taverne" license above, please 


\section{Discussion of "Rigid Water Column Model for Simulating the Emptying Process in a Pipeline Using Pressurized Air" by Oscar E. Coronado-Hernández, Vicente S. Fuertes-Miquel, Pedro L. Iglesias-Rey, and Francisco J. Martínez-Solano}

\begin{abstract}
Qingzhi Hou
Associate Professor, State Key Laboratory of Hydraulic Engineering Simulation and Safety, Tianjin Univ., 135 Yaguan Rd., Tianjin 300350, China; College of Intelligence and Computing, Tianjin Univ., 135 Yaguan Rd., Tianjin 300350, China (corresponding author). Email: qhou@tju .edu.cn
\end{abstract}

\section{Shunda Li}

Graduate Student, College of Intelligence and Computing, Tianjin Univ., 135 Yaguan Rd., Tianjin 300350, China. Email: sdli9509@163.com

\section{Arris S. Tijsseling}

Associate Professor, Dept. of Mathematics and Computer Science, Eindhoven Univ. of Technology, P.O. Box 513, Eindhoven, 5600 MB, Netherlands. Email: a.s.tijsseling@tue.nl

\section{Janek Laanearu}

Associate Professor, School of Engineering, Dept. of Civil Engineering and Architecture, Tallinn Univ. of Technology, Ehitajate tee 5, Tallinn 19086, Estonia. Email: janek.laanearu@taltech.ee

\section{https://doi.org/10.1061/(ASCE)HY.1943-7900.0001446}

Emptying pipelines is a typical procedure engineers must face in water supply and sewer networks. In pipeline emptying, an initially very long liquid column becomes very short and may accelerate to high velocities due to driving gas, liquid mass loss (i.e., outflow and column tail leakage), and gravity, thereby imposing serious impact forces on the pipeline system. As a typical process closely related to pipeline emptying, geysering in the drop shaft of rainstorm tunnel systems has recently received much attention (Cong et al. 2017; Vasconcelos and Wright 2011; Wright et al. 2011; Li et al. 2019). The transient phenomena occurring in the emptying process can be analyzed using the elastic water column model (EWCM) and the rigid water column model (RWCM). The authors presented an RWCM and validated it against the experiments performed by the discussers in a large-scale pipeline. The authors concluded that the basic model they used can more precisely predict water flows and gauge pressures than previous models. However, the discussers do not fully agree with this conclusion because several key experimental parameters were tuned and are different from the measured ones, especially the initial water column length and the pipe friction factor. The discussers wish to comment and elaborate on the rigid column mathematical model.

\section{Experimental Apparatus and Its Parameters}

An experimental study of pipeline emptying has been performed by Laanearu et al. (2012). The authors compared their numerical results with these experiments and the parameters need to be clarified in detail for our discussion.

The experimental setup of the large-scale pipeline apparatus initially filled with water and connected to a tank with compressed air was described by Laanearu et al. (2012). The pipeline consists of $275.2 \mathrm{~m}$ of PVC pipe connected upstream and downstream to steel pipes with lengths of 29.1 and $9.8 \mathrm{~m}$, respectively, giving a total length of $314.1 \mathrm{~m}$. The scaled computer-aided design (CAD) drawing with measuring instruments is depicted in Fig. 1 herein and the corresponding coordinates are shown in Fig. 1 in Hou et al. (2014). To ensure that the initial air-water interface is positioned at the check valve, a small-size ventilation valve on top of the pipe (not shown), close to the check valve, is opened before every emptying test to expel all air from the system and it is closed after a steady water jet has formed.

Except for the preceding geometrical parameters, other experimental parameters including friction factor and head-loss coefficients in the pipeline apparatus were determined using the Darcy-Weisbach formula. The head loss due to the $180^{\circ}$ turn and the $90^{\circ}$ turns can be ignored; this was verified by steady-state measurements with the end valve fully open (Laanearu et al. 2012). The measured flow rates together with time-averaged pressure heads from Transducers P1 and P9 were then used to calculate the values of the friction factor in the PVC pipeline. The calculated friction factor was 0.0136 , which indicates a relative wall roughness of 0.00011 and corresponding roughness size of $0.026 \mathrm{~mm}$. The estimated wall roughness size was much larger than that of the small-diameter $(D=22.9 \mathrm{~mm})$ PVC pipe used in the filling experiments of Liou and Hunt (1996), which was $0.0034 \mathrm{~mm}$, noting that handbooks give a nominal value of $0.0015 \mathrm{~mm}$. If this smaller roughness size were used, the corresponding pipe friction factor would be the value used by the authors in the original paper: $f=0.0117$. When the end valve is not fully open, the Reynolds number is smaller and the friction factor is larger. This fact has not been taken into account in previous numerical simulations (e.g., Laanearu et al. 2012; Tijsseling et al. 2016) and in the original paper.

\section{RWCMs for Pipeline Emptying}

For the modeling of pipeline emptying, RWCMs seem to be adequate and three representative models need to be underlined, including those of Laanearu et al. (2012), Tijsseling et al. (2016), and the authors. Consider the schematized liquid column in a horizontal-vertical pipeline as sketched in Fig. 2. The pressure is $P_{1}$ downstream of the outlet valve and it is $P_{2}$ at the air-water interface. The outflow velocity is $U$. The water column has variable length $L$ and constant density $\rho$. In the ideal emptying process, the column length decreases from full pipe length $L_{P}$ to zero. The common assumptions made to describe the motion of the liquid column are that (1) one-directional motion takes place along the pipe axis, (2) shear resistance to liquid motion is as in quasi-steady 


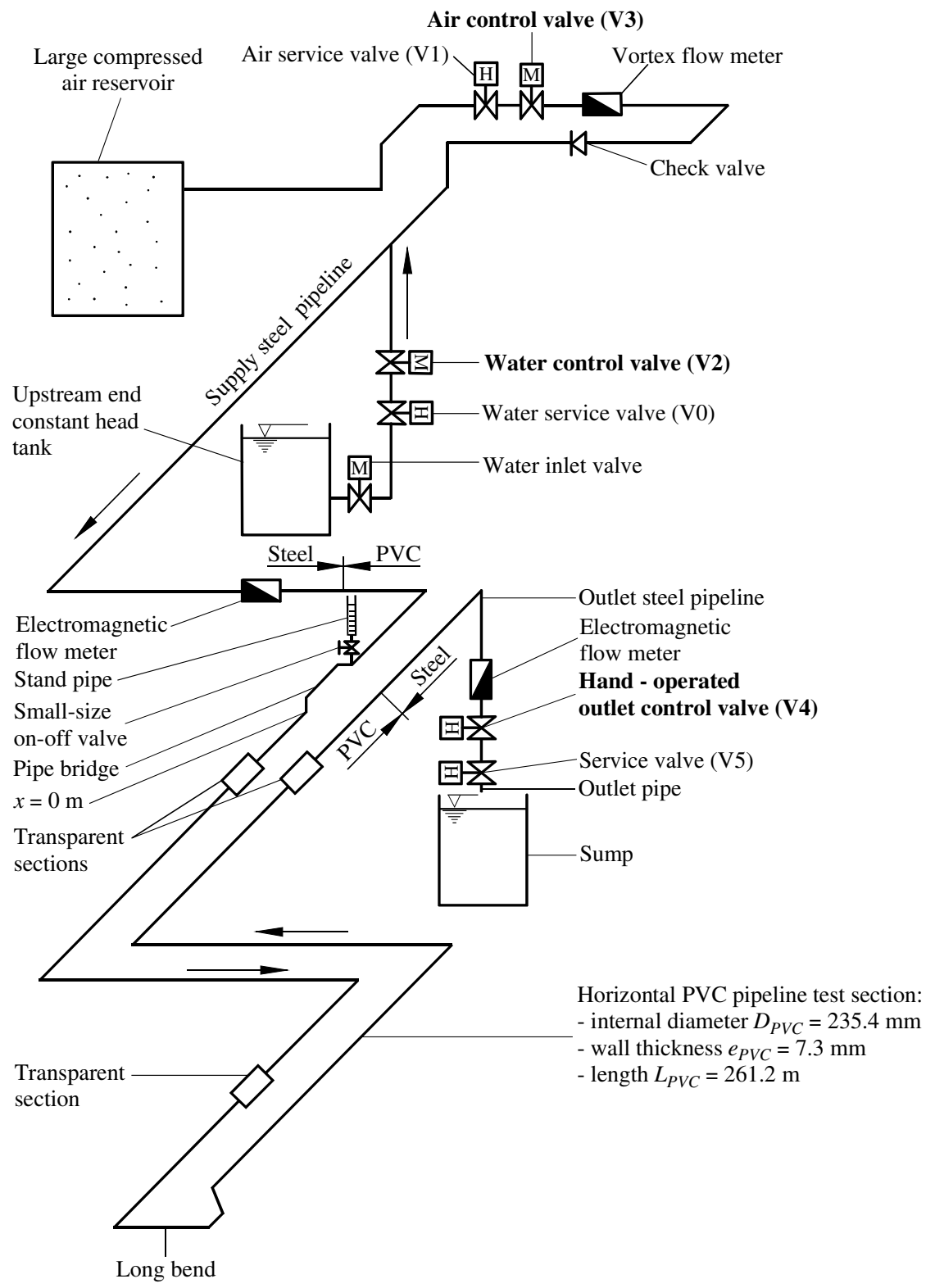

Fig. 1. Sketch of the experimental apparatus for emptying of a large-scale pipeline.

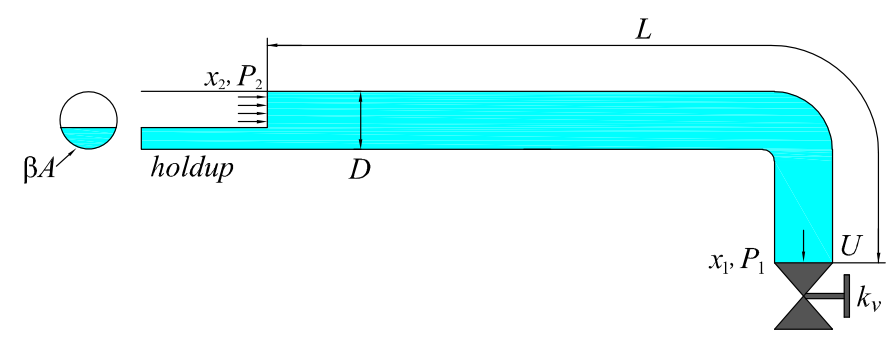

Fig. 2. Sketch of the emptying of a pipeline with horizontal-vertical profile.

flow, and (3) the air-water interface remains planar, no matter whether holdup forms or not (Fig. 2). The holdup represents the liquid that is left behind the advancing water column as a result of gravity and shearing effects. It is accounted for by a coefficient $\beta(0 \leq \beta \leq 1)$, such that the amount of mass lost per unit length is $\rho \beta A$, where $A$ is the cross-sectional area.
The key differences between the three representative models are mainly because of the following concerns:

- Does the air-water interface change its shape significantly in the emptying process, or equivalently, does water stratification due to air intrusion and mass shedding occur?

- When holdup forms, is the flow velocity in the water column taken as uniform or linearly decreasing from the air-water interface to the downstream control valve?

- When holdup forms, how is its momentum defined and/or calculated?

Tijsseling et al. (2016) assumed that (1) mass loss occurs proportional to the tail's velocity such that holdup of constant height forms; (2) owing to mass loss at its tail, the flow velocity in the water column is linearly decreasing from the air-water interface to the downstream control valve; and (3) the velocity of the holdup is zero, i.e., the holdup sticks to the wall. From the principles of conservation of mass and momentum, Tijsseling et al. (2016) derived the following equations describing pipeline emptying: 

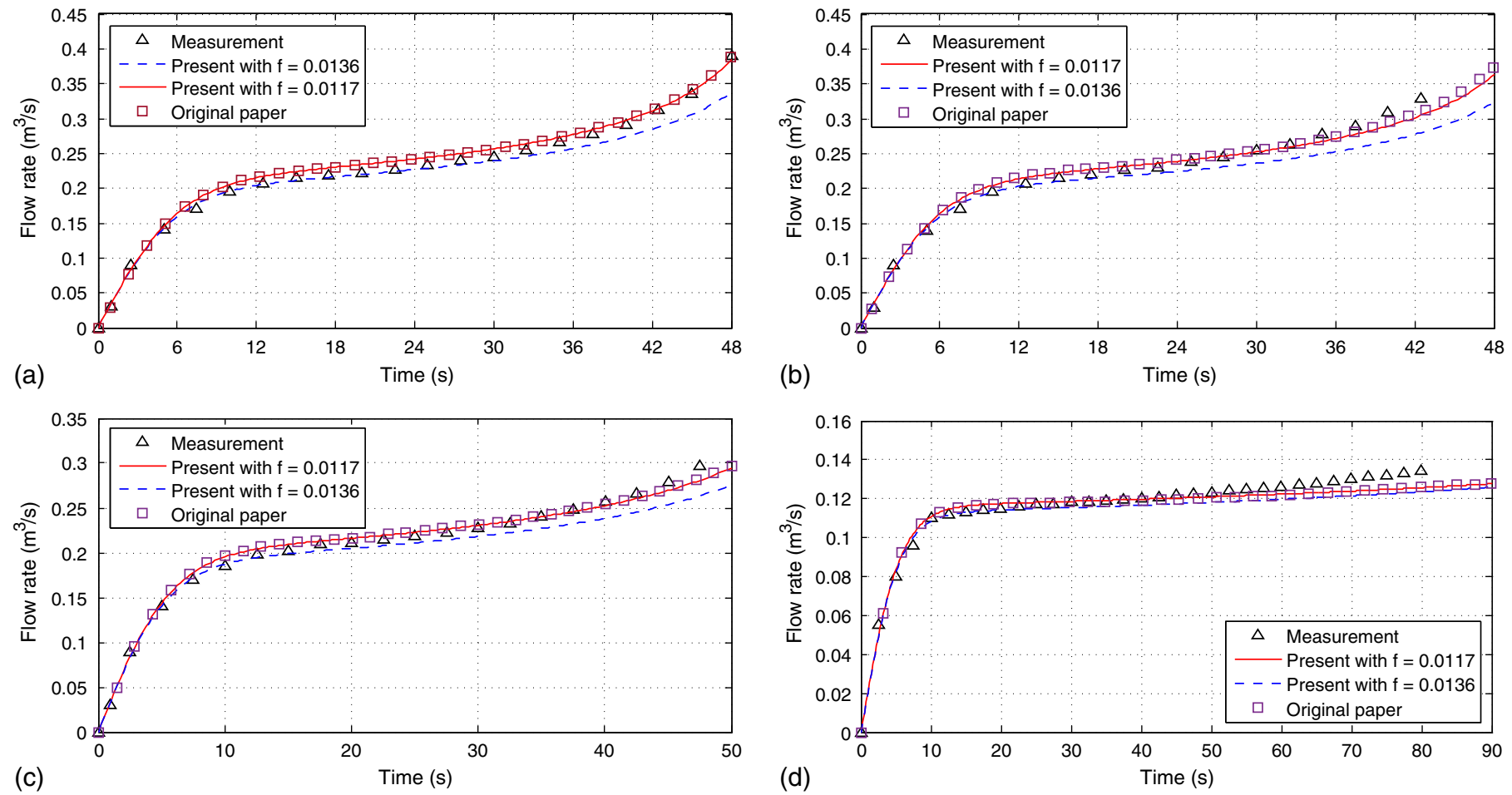

Fig. 3. Comparisons between the modeled and measured flow rates: (a) Run 1; (b) Run 4; (c) Run 5; and (d) Run 9.

$$
\begin{gathered}
\frac{1-\frac{1}{2} \beta}{1-\beta} \frac{d U}{d t}=\frac{\beta}{1-\beta} \frac{U^{2}}{L}+\frac{P_{2}-P_{1}}{\rho L}+\frac{g}{L}\left[z\left(x_{2}\right)-z\left(x_{1}\right)\right] \\
-\frac{f}{2 D} \frac{1-\beta+\frac{1}{3} \beta^{2}}{(1-\beta)^{2}} U^{2}-\frac{K_{v}}{2 L} U^{2} \\
\frac{d L}{d t}=-\frac{1}{1-\beta} U \\
\frac{d x_{2}}{d t}=\frac{1}{1-\beta} U
\end{gathered}
$$

where $z(x)=$ elevation at position $x$; and $K_{v}=$ head-loss coefficient of the outlet control valve. The velocity of the moving air-water interface is $U /(1-\beta)$. In addition, because no return flow occurs in the emptying process (i.e., $U \geq 0$ ), $U^{2}=U|U|$.

Laanearu et al. (2012) assumed that (1) mass loss occurs at a changing rate in the emptying process and hence holdup with variable height forms, (2) the flow velocity in the water column is uniform, and (3) the velocity of the holdup is nonzero. EWCM and RWCM do not represent specifically the control volume (CV) model introduced by Laanearu et al. (2012). One aspect of this theoretical CV approach is that the nonzero holdup yields a residual momentum problem. The residual momentum changes due to the outflow boundary and the internal motion relative to the chosen control volume and is represented by an integral coefficient (Laanearu et al. 2012, 2014), which is related to the holdup coefficient by a functional relationship

$$
\gamma=1+\frac{1-\beta}{\beta} \frac{1}{U^{2}} \int_{\text {residual }} \frac{\partial U_{r}}{\partial t} d s
$$

where $U_{r}=$ relative velocity. The momentum equation thus becomes

$$
\begin{aligned}
\frac{d U}{d t}= & \left(\frac{\gamma \beta}{1-\beta}-1\right) \frac{U^{2}}{L}+\frac{P_{2}-P_{1}}{\rho L}+\frac{g}{L}\left[z\left(x_{2}\right)-z\left(x_{1}\right)\right] \\
& -\frac{f}{2 D} U^{2}-\frac{K_{v}}{2 L} U^{2}
\end{aligned}
$$

With $\gamma=1 / \beta$, the corresponding term in Eq. (1) is retrieved. The water column changes its length according to Eq. (2) and the airwater interface changes its position according to Eq. (3). To establish agreement between the experimental and theoretical results, the timedependent coefficients $\beta$ and $\gamma$ were data-fitted by Laanearu et al. (2012) since they represent the complex interplay of the formation of stratified flow and the change of flow momentum at the air-water interface. Recently, Korzilius et al. (2017) found that $\beta$ is nearly constant for relatively short slugs accelerating in an inclined pipe.

The authors assumed that no mass shedding occurs during the emptying process and hence the flow velocity in the water column is uniform. Their momentum equation for the emptying column is then

$$
\frac{d U}{d t}=\frac{P_{2}-P_{1}}{\rho L}+\frac{g}{L}\left[z\left(x_{2}\right)-z\left(x_{1}\right)\right]-\frac{f}{2 D} U^{2}-\frac{K_{v}}{2 L} U^{2}
$$

The water column changes its length according to

$$
\frac{d L}{d t}=-U \quad \text { or } \quad x_{2}=\int_{0}^{t} U d t
$$

It is clear that the authors' model is the simplest (which may have its advantages) among the three representative models. It is a special case of the model of Tijsseling et al. (2016) with $\beta=0$.

\section{Model Validation}

For verification, the model of Tijsseling et al. (2016) with $\beta=0$ is applied to the experiments of Laanearu et al. (2012). Using the parameters listed in Table 1 of the original paper, the calculated 


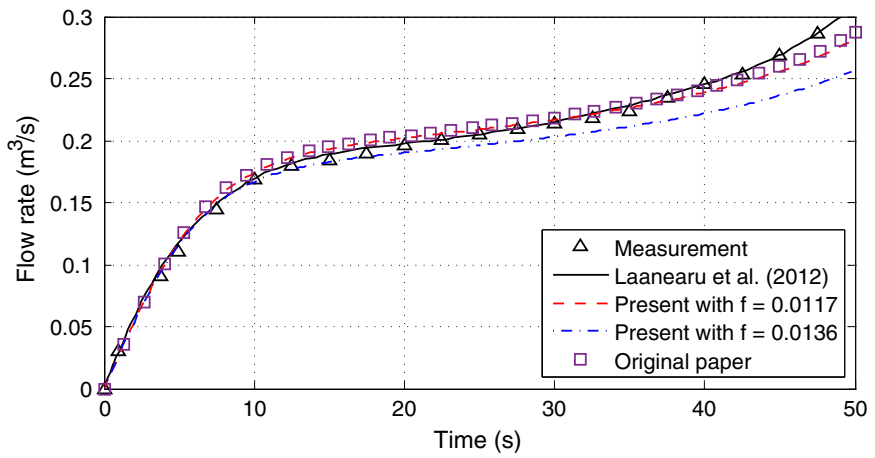

Fig. 4. Comparisons between the modeled and measured flow rates for Run 2.

water flow rates for Runs 1, 4, 5, and 9 are shown in Fig. 3 together with the measurements. Two different friction factors were used. One is the experimentally determined value of $f=0.0136$, and the other is the lower value of $f=0.0117$ as used for a much smaller pipe in the experiment of Liou and Hunt (1996). With the smaller friction factor $f=0.0117$, better agreement with the measurements is obtained. With the larger friction factor $f=$ 0.0136, the flow rates are smaller, except during a period of $6 \mathrm{~s}$ at the beginning of the event. It is evident that larger friction decreases the column's acceleration. The results are almost the same as those of the authors; there is only a slight difference because a linearly decreasing driving gauge pressure (i.e., $\mathrm{d} P_{2} / \mathrm{d} t=$ constant) is used in the present model and not the measured values (shown in the original paper's Fig. 3) used by the authors.

With the friction factor $f=0.0136$, tuned initial water column lengths, and tuned parameters $\beta$ and $\gamma$ in the model of Laanearu et al. (2012), even better agreements with the measurements can be obtained as is evident from Fig. 4.

In the simulations by Laanearu et al. (2012), the initial water column length was used parametrically because this quantity was not directly measured in the experimental runs, it is tuned for different runs. When the correct initial length of $L=314.1 \mathrm{~m}$ is applied with $f=0.0136$ and $\beta=0$, the results for Runs 2 and 6 are shown in Fig. 5. It is clear that without considering the holdup effect, the simulated flow rate is smaller than in the experiments. Without mass shedding (i.e., holdup), the water column is longer with larger mass and higher skin friction, and hence its acceleration and velocity are smaller. Mass shedding has been observed in all the experiments and therefore it must be taken into account in a realistic model. The solutions of the model without holdup $(\beta=0)$ of Tijsseling et al. (2016) are also presented in Fig. 5 and the small differences in the early stage are mainly due to the neglected elevation changes at the pipe bridge and upstream vertical leg (Fig. 1) in the current simulations. In Run 6 the valve is partly closed; the Reynolds number based on outflow velocity is then 824,000 so that the friction factor increases to $f=0.0139$.

Furthermore, in Fig. 5 the numerical results of Tijsseling et al. (2016) including the holdup effect are displayed for comparison. The holdup coefficient is constant but case dependent based on estimates of remaining water [Table 2 in Tijsseling et al. (2016)]. It is clear that, taking the holdup effect into account, the resulting propulsion is slightly and largely overestimated in Runs 2 and 6, respectively. With $50 \%$ reduced holdup coefficients $(\beta=0.13)$, the agreements are much improved, especially for the early stage of the emptying process. In addition to the too large holdup coefficients used, there are three other possible reasons for the discrepancies:

- The assumption that the velocity of the holdup is zero is questionable and not consistent with the experimental observation that the shed mass moves with the water column especially in the early stages of the emptying process (Laanearu et al. 2015).

- The constant holdup coefficient is a crude assumption for the modeling of the pipeline emptying process. It might be reasonable for steady slug flow, but it introduces large uncertainty for unsteady flows such as the rapid emptying process studied herein. However, it is not an easy task to determine a variable holdup coefficient.

- The water hammer effect disturbs both initial acceleration and planar air-water interface.

\section{Pressure Calculation}

The pressure in a pipeline when drained is

$P(x, t)= \begin{cases}P_{2}(t) & \text { if } 0 \leq x<x_{2}(t) \\ -\rho g z(x)+\frac{x-x_{2}(t)}{L(t)}\left(P_{1}(t)+\rho g z\left(x_{1}\right)+\frac{K_{v}}{2} \rho(1-\beta)^{2} v_{2}^{2}(t)\right)+\frac{x-x_{2}(t)}{L(t)}\left(P_{2}(t)+\rho g z\left(x_{2}(t)\right)\right) & \text { if } x_{2}(t) \leq x \leq x_{1}=x_{L}\end{cases}$

where $P_{2}=$ driving pressure; and $v_{2}=$ velocity of the air-water front. The hydraulic grade line in a rigid column is linear and not the pressure as mistakenly assumed in Eq. (10) in Tijsseling et al. (2016), where the pressures calculated for pipe filling are also incorrect. Fig. 6 is corrected accordingly and it is now consistent with Fig. 7 in the original paper.

\section{Discussion}

The authors used a rigid column model to study the variations of flow and pressure in the emptying process of a pipeline using pressurized air. The most questionable assumption in the model developed by the authors is that the air-water interface is well defined and remains unchanged in the emptying process. This was clearly not the case in the simulated experiments. With well-selected parameters, the authors obtained good agreement between numerical and experimental results. The discussers demonstrate that larger deviations are found when correct parameters, including friction factor, initial water column length, and holdup coefficient, are used. The following observations may be useful for the development of reliable rigid column models and for the analysis of the pipeline emptying experiment of Laanearu et al. (2012): 


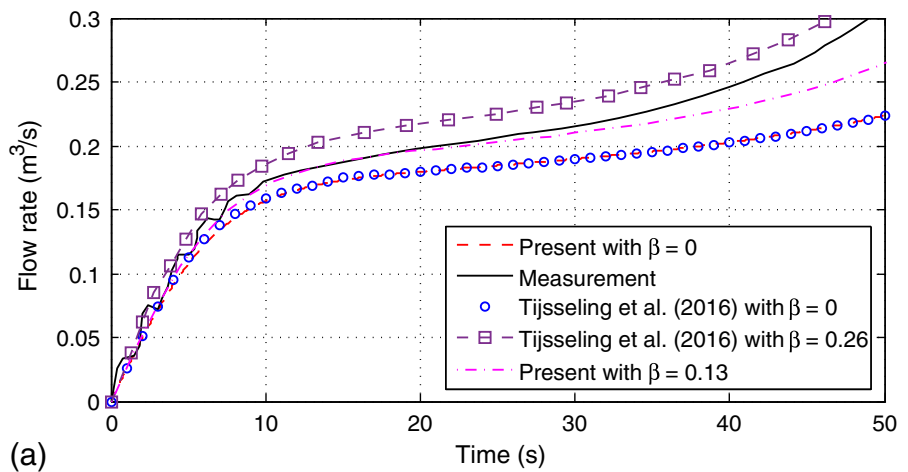

Fig. 5. Comparisons between the modeled and measured flow rates: (a) Run 2; and (b) Run 6 .

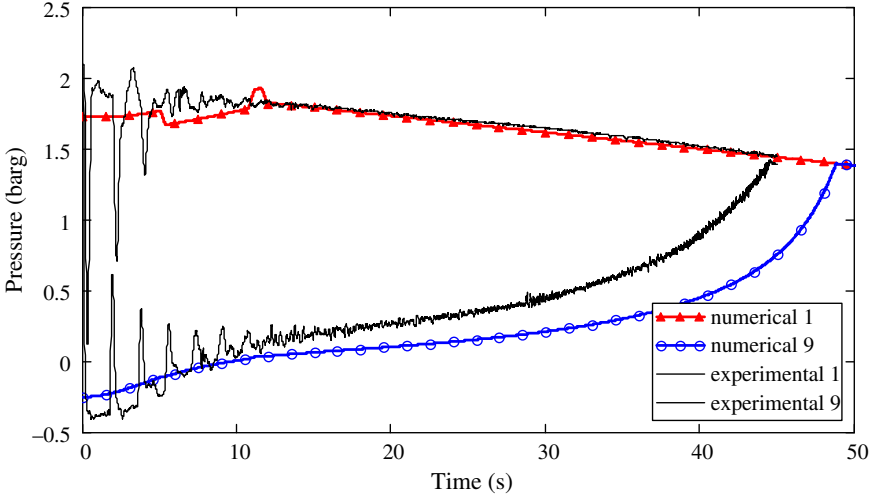

Fig. 6. Pressures at Measurement sections 1 and 9 for emptying Run 4 (Repetition 2): measured (continuous curves) and calculated (marked curves) histories.

- The friction factor $f=0.0136$ is experimentally determined at maximum flow rate. At lower flow rates the friction factor must be taken slightly larger.

- The initial length of the water column is $341.1 \mathrm{~m}$ and not lower than that.

- The actual undulation profile of the pipeline must be taken into account, where the effect of the pipe bridge and the upstream vertical leg is negligible, but not so the effect of the downstream vertical leg.

- It is questionable that different loss coefficients $K_{v}$ were obtained for the same openings of the downstream control valve, although manual operations might give rise to small variations.

- The assumption of uniform flow velocity in the RWCM for pipeline emptying cannot be accepted when the flow inside the pipe is stratified behind the column's tail, in which case the air-water front moves faster than the average outflow.

- The pipeline emptying experiments by Laanearu et al. (2012) demonstrated clearly the increase of the holdup parameter $\beta$ during the air-water front motion along the pipeline, and therefore the complex interplay of the formation of stratified flow and the change of flow momentum at the air-water interface is apparent.

- The pressure Eq. (10) in Tijsseling et al. (2016) is not valid for nonhorizontal pipelines.

- Another apparent inconsistency of the authors' model is shown in their Table 1. When the measured and modeled velocities are compared, the velocity differences are significant in some cases, e.g., differences of $0.5 \mathrm{~m} / \mathrm{s}$ and more, and not acceptable. However, the pressures are perfectly predicted. This seems questionable.

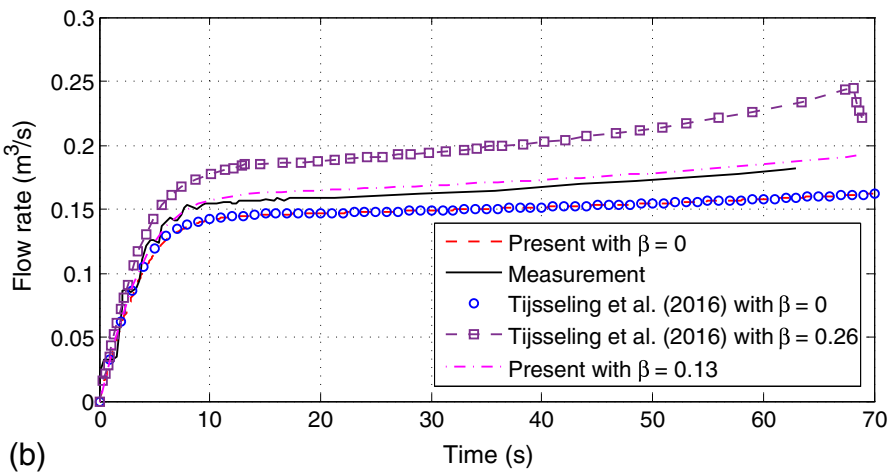

- One interesting point from the observations of stratified flow in the laboratory in Delft, Netherlands (Laanearu et al. 2012) was that the pipeline remained empty at Measurement section 1, which indicates that stratified flow appears at some location inside the PVC pipe. This condition is absent in the original paper but taken into account by Laanearu et al. (2012).

- The sensitivity of RWCM to its input parameters friction factor and holdup coefficient is demonstrated.

Despite the comments expressed, the discussers welcome the authors' contribution because there are not many studies dealing with the modeling of flow and pressure variations in the process of pipeline emptying. The authors have shown that when using appropriate parameters, RWCM in its simplest form is able to accurately describe the rapid emptying of a pipeline. Their results are fully consistent with those of the discussers, who were forced to have a critical look at their own results. As a positive outcome, an omission in the pressure calculation by Tijsseling et al. (2016) has been corrected.

\section{Acknowledgments}

The discussers gratefully acknowledge the financial support from the National Natural Science Foundation of China (Grant Nos. 51478305 and U1765202) and the National Key Research and Development Program of China (Grant No. 2016YFC0401900).

\section{References}

Cong, J., S. N. Chan, and J. H. W. Lee. 2017. "Geyser formation by release of entrapped air from horizontal pipe into vertical shaft." J. Hydraul. Eng. 143 (9): 04017039. https://doi.org/10.1061/(ASCE)HY.1943 $-7900.0001332$

Hou, Q., A. S. Tijsseling, J. Laanearu, I. Annus, T. Koppel, A. Bergant, S. Vučkovič, and A. Anderson, and J. M. C. van't Westende. 2014. "Experimental investigation on rapid filling of a large-scale pipeline." J. Hydraul. Eng. 140 (11): 04014053. https://doi.org/10.1061/(ASCE) HY.1943-7900.0000914.

Korzilius, S. P., A. S. Tijsseling, Z. Bozkuş, M. J. H. Anthonissen, and W. H. A. Schilders. 2017. "Modeling liquid slugs accelerating in inclined conduits." J. Pressure Vessel Technol. 139 (6): 1-10. https://doi .org/10.1115/1.4037716.

Laanearu, J., I. Annus, T. Koppel, A. Bergant, S. Vučkovič, Q. Hou, A. S. Tijsseling, A. Anderson, and J. M. C. van't Westende. 2012. "Emptying of large-scale pipeline by pressurized air." J. Hydraul. Eng. 138 (12): 1090-1100. https://doi.org/10.1061/(ASCE)HY.1943-7900.0000631.

Laanearu, J., I. Annus, M. Sergejeva, and T. Koppel. 2014. "Semiempirical method for estimation of energy losses in a large-scale pipeline." Procedia Eng. 70: 969-977. https://doi.org/10.1016/j .proeng.2014.02.108. 
Laanearu, J., Q. Hou, I. Annus, and A. S. Tijsseling. 2015. "Water-column mass losses during the emptying of a large-scale pipeline by pressurized air." Proc. Est. Acad. Sci. 64 (1): 8-16. https://doi.org/10.3176/proc 2015.1.02.

Li, C., B. K. Campbell, Y. Liu, and K. P. Yue. 2019. "A fast multi-layer boundary element method for direct numerical simulation of sound propagation in shallow water environments." J. Comput. Phys. 392 (Sep): 694-712. https://doi.org/10.1016/j.jcp.2019.04.068

Liou, C. P., and W. A. Hunt. 1996. "Filling of pipelines with undulating elevation profiles." J. Hydraul. Eng. 122 (10): 534-539. https://doi.org/10.1061/(ASCE)0733-9429(1996)122:10(534).
Tijsseling, A. S., Q. Hou, Z. Bozkus, and J. Laanearu. 2016. "Improved one-dimensional models for rapid emptying and filling of pipelines." J. Pressure Vessel Technol. 138 (3): 031301. https://doi.org/10.1115/1 .4031508 .

Vasconcelos, J. G., and S. J. Wright. 2011. "Geysering generated by large air pockets released through water-filled ventilation shafts." J. Hydraul. Eng. 137 (5): 543-555. https://doi.org/10.1061/(ASCE)HY.1943-7900 .0000332 .

Wright, S. J., J. W. Lewis, and J. G. Vasconcelos. 2011. "Geysering in rapidly filling storm-water tunnels." J. Hydraul. Eng. 137 (1): 112-115. https://doi.org/10.1061/(ASCE)HY.1943-7900.0000245. 